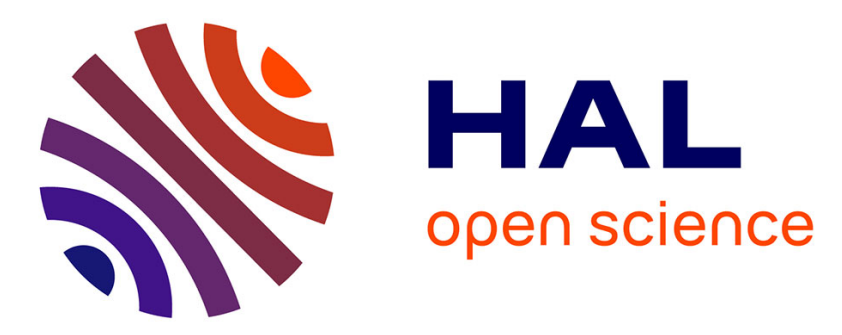

\title{
Conduction disturbances following trancatheter aortic valve implantation: increasing the 'pace' towards prospective evidence
}

\author{
Vincent Auffret, Rishi Puri, Guillaume Leurent, Hervé Le Breton
}

\section{To cite this version:}

Vincent Auffret, Rishi Puri, Guillaume Leurent, Hervé Le Breton. Conduction disturbances following trancatheter aortic valve implantation: increasing the 'pace' towards prospective evidence. European Heart Journal, 2020, 41 (29), pp.2782-2784. 10.1093/eurheartj/ehz957 . hal-02470873

HAL Id: hal-02470873

https://hal-univ-rennes1.archives-ouvertes.fr/hal-02470873

Submitted on 12 May 2020

HAL is a multi-disciplinary open access archive for the deposit and dissemination of scientific research documents, whether they are published or not. The documents may come from teaching and research institutions in France or abroad, or from public or private research centers.
L'archive ouverte pluridisciplinaire HAL, est destinée au dépôt et à la diffusion de documents scientifiques de niveau recherche, publiés ou non, émanant des établissements d'enseignement et de recherche français ou étrangers, des laboratoires publics ou privés. 


\section{Conduction Disturbances Following Trancatheter Aortic Valve Implantation: Increasing the "Pace" Towards Prospective Evidence}

Vincent Auffret, MD PhD ${ }^{1}$, Rishi Puri, MBBS $\mathrm{PhD}^{2}$, Guillaume Leurent, $\mathrm{MD}^{1}$, Hervé Le Breton, $\mathrm{MD}^{1}$.

\section{Authors affiliations :}

1. Université de Rennes 1, Service de Cardiologie CHU Rennes, Inserm LTSI U1099, F 35000 Rennes, France

2. Department of Cardiovascular Medicine and Cleveland Clinic Coordinating Center for Clinical Research (C5Research), Cleveland Clinic, Cleveland, OH, USA.

Word count:1817

Conflict of interest disclosure: Dr Vincent Auffret received lecture fees from Edwards Lifesciences. Dr Rishi Puri has received consulting fees from Medtronic. Dr Leurent received speaker and consultant fees from Abbott, and Novartis, and speaker fees from Abiomed, and AstraZeneca. Dr Le Breton received lecture fees from Edwards Lifescences.

Address for correspondence:

Vincent Auffret, MD, PhD

Service de Cardiologie

CHU Pontchaillou

2 rue Henri Le Guilloux, 35033 Rennes, France.

Phone: + 33299282 505, Fax: +33 29928253

Email: vincent.auffret@chu-rennes.fr 
After a well-coordinated series of randomized clinical trials conducted over the last 10 years, transcatheter aortic valve implantation (TAVI) is poised to emerge as the first-line treatment among patients with symptomatic severe aortic stenosis regardless of the estimated surgical risk $^{1,2}$. Asides from bicuspid valve disease and understanding the true durability in younger patients, TAVIs effects upon conduction system and the subsequent longer-term consequences of these effects remain to be prospectively explored, representing the last frontier for this disruptive technology.

Over time, TAVI has steadily overcome the numerous hurdles standing in its way. However, a few concerns remain going forwards. Among them, conduction disturbances (i.e. new-onset persistent left bundle branch block [LBBB] and permanent pacemaker implantation [PPI], represent the most common complications of this paradigm-changing therapy ${ }^{3}$. Newonset LBBB has been reported in approximately 25\% (4-65\%) of first generation transcatheter heart valve recipients while data regarding its occurrence with newer-generation devices are relatively scarce with a reported incidence ranging from 10 to $70 \%{ }^{3,4}$. Similarly, a wide variation in reported rates of PPI (2 to 51\%) has been observed with first generation devices with a pooled incidence of $13 \%{ }^{3}$. Of note, rates of PPI did not decrease with newer-generation devices $^{3}$. Contrasting with this high incidence of conduction disturbances post-TAVR is the paucity of longer-term prospective data to better inform the impact upon subsequent PPI (for new-onset LBBB), heart failure hospitalisations and mortality. This latter point has been the subject of numerous individual studies reaching conflicting conclusions ${ }^{3,5-9}$. Several metaanalyses failed to demonstrate a meaningful association between new-onset LBBB or PPI and all-cause mortality $^{10,11}$. Nonetheless, a significant association between new-onset LBBB and an increased cardiac mortality was suggested, whereas PPI per se tended to associate with decreased cardiac mortality post-TAVI ${ }^{11}$. More recent studies unravelled conflicting results posing a conundrum, making it difficult for clinicians to accurately counsel patients when 
discussing the most appropriate therapeutic strategy to apply to those eligible both to TAVI or surgical aortic valve replacement (SAVR) $)^{5,7-9}$. Although post-TAVI rates of PPI are well within single-digit percentages in expert centres, and were comparable after SAVR and TAVI with a balloon-expandable valve in low-risk patients, the occurrence of new-onset LBBB remained more than 3-fold higher post-TAVI ${ }^{2}$. This issue is of paramount importance if TAVI is to ultimately succeed in even younger, healthier patients requiring aortic valve replacement in whom the detrimental consequences of conduction disturbances and right ventricular pacing could translate into deleterious cardiac outcomes.

The path forwards leading to a more complete understanding of the long-term clinical impact of conduction disturbances post-TAVI remains somewhat cumbersome. Nonetheless, in this issue of the European Heart Journal, Faroux et al ${ }^{12}$ took another step towards this goal. The authors performed an updated systematic review and meta-analysis of studies reporting raw data on 1-year clinical impact of new-onset persistent LBBB or periprocedural PPI post-TAVI. The outcomes of interest included mortality (all-cause and cardiovascular), and rehospitalisation for heart failure for both complications as well as the need for PPI for new-onset LBBB. Thirty studies were deemed eligible for the analysis, including 12 studies (7792 patients) and 21 studies (42927 patients) for the assessment of the clinical impact of new-onset persistent LBBB, and PPI post-TAVI, respectively. New-onset LBBB was significantly associated with a higher 1-year risk of PPI, rehospitalisation for heart failure, allcause, and cardiovascular mortality. Similarly, PPI demonstrated a detrimental association with the 1-year risk of heart failure readmission, and all-cause mortality whereas no significant effect on cardiac death was observed.

Meta-analyses, particularly those undertaken at a study-level, do not allow a stringent adjustment of confounders, and are inherently limited by the nuances of the included studies. Besides this limitation, its retrospective designs, along with varying definitions and selected 
time points for new-onset LBBB and PPI, a lack of ascertainment of the persistence of LBBB at the time of death, the different inter-study thresholds that prompted PPI, or exclusion of death within 30-days of the TAVI procedure in certain studies, represent a number of biases, which may have affected the results. The lack of data regarding baseline ejection fraction, type of pacemakers (acknowledged by authors), specific causes of death (e.g. sudden cardiac death), and the absence of granularity concerning pacing percentage at follow-up are other shortcomings that come to mind. Thus, the exact nature of the association between conduction disturbances and a worse prognosis post-TAVI remains elusive. However, despite these limitations, this study is at the very least thought-provoking. If the effects of post-TAVI conduction disturbances described by Faroux et al truly represent their genuine clinical impact, then we must pause and reflect upon the path forwards with TAVI ${ }^{12}$. As such, these findings warrant the analysis of robust prospective (even randomized in some cases) data of the incidence, natural history, and management of post-TAVI conduction disturbances. In particular, the exact role of electrophysiological studies, patch ECG recorders, and implantable loop recorders in the management of new-onset LBBB or transient high-degree atrioventricular block should be delineated (Take-home Figure). Moreover, some recent studies questioned the class effect of TAVI, suggesting that not all transcatheter heart valve's designs are equal, especially regarding conduction disturbances ${ }^{13,14}$. Collectively, these observational data, along with the meta-analysis by Faroux et $\mathrm{al}^{12}$, should ultimately spur adequately-powered randomized comparisons of the commercially-available valves most commonly implanted in routine practice. Acknowledging that the risk of conduction disturbances cannot be the only decisional element, such data are urgently needed to inform clinician's choice when facing patients suitable for most transcatheter heart valve designs. That being said, what should we be doing in the interim pending the availability of these prospective data, particularly over the longer term? Preventing or minimizing conduction 
disturbances during TAVI represents an important challenge in contemporary practice. Avoiding excessive prosthesis oversizing or manipulation, and aiming at a more aortic position are simple procedural features that may reduce their occurrence. In case of transient conduction disturbances post-TAVI, physicians should resist the urge for early PPI and adopt a watch and wait approach, even it means prolonging length of stay in some cases. Finally, despite a lack of prospective evidence, we should tend towards a more uniform management of conduction disturbances which has been advocated in a recent experts' position paper ${ }^{4}$. Faroux et al should be commended for performing this work sending the cardiologic community a clear message: 'Be careful!' We cannot afford to neglect the issue of post-TAVI conduction disturbances anymore. 


\section{REFERENCES}

1. Popma JJ, Deeb GM, Yakubov SJ, Mumtaz M, Gada H, O’Hair D, Bajwa T, Heiser JC, Merhi W, Kleiman NS, Askew J, Sorajja P, Rovin J, Chetcuti SJ, Adams DH, Teirstein PS, Zorn GL 3rd, Forrest JK, Tchetche D, Resar J, Walton A, Piazza N, Ramlawi B, Robinson N, Petrossian G, Gleason TG, Oh JK, Boulware MJ, Qiao H, Mugglin AS, et al. Transcatheter Aortic-Valve Replacement with a Self-Expanding Valve in Low-Risk Patients. N Engl J Med 2019; 380:1706-1715.

2. Mack MJ, Leon MB, Thourani VH, Makkar R, Kodali SK, Russo M, Kapadia SR, Malaisrie SC, Cohen DJ, Pibarot P, Leipsic J, Hahn RT, Blanke P, Williams MR, McCabe JM, Brown DL, Babaliaros V, Goldman S, Szeto WY, Genereux P, Pershad A, Pocock SJ, Alu MC, Webb JG, Smith CR. Transcatheter Aortic-Valve Replacement with a Balloon-Expandable Valve in Low-Risk Patients. N Engl J Med 2019; 380:1695-1705.

3. Auffret V, Puri R, Urena M, Chamandi C, Rodriguez-Gabella T, Philippon F, RodesCabau J. Conduction Disturbances After Transcatheter Aortic Valve Replacement: Current Status and Future Perspectives. Circulation 2017;136:1049-1069.

4. Rodes-Cabau J, Ellenbogen KA, Krahn AD, Latib A, Mack M, Mittal S, Muntane-Carol G, Nazif TM, Sondergaard L, Urena M, Windecker S, Philippon F. Management of Conduction Disturbances Associated With Transcatheter Aortic Valve Replacement: JACC Scientific Expert Panel. J Am Coll Cardiol 2019;74:1086-1106.

5. Chamandi C, Barbanti M, Munoz-Garcia A, Latib A, Nombela-Franco L, GutierrezIbanez E, Veiga-Fernandez G, Cheema AN, Cruz-Gonzalez I, Serra V, Tamburino C, Mangieri A, Colombo A, Jimenez-Quevedo P, Elizaga J, Laughlin G, Lee DH, Garcia Del Blanco B, Rodriguez-Gabella T, Marsal JR, Cote M, Philippon F, Rodes-Cabau J. Long- 
Term Outcomes in Patients With New Permanent Pacemaker Implantation Following Transcatheter Aortic Valve Replacement. JACC Cardiovasc Interv 2018;11:301-310.

6. Fadahunsi OO, Olowoyeye A, Ukaigwe A, Li Z, Vora AN, Vemulapalli S, Elgin E, Donato A. Incidence, Predictors, and Outcomes of Permanent Pacemaker Implantation Following Transcatheter Aortic Valve Replacement: Analysis From the U.S. Society of Thoracic Surgeons/American College of Cardiology TVT Registry. JACC Cardiovasc Interv 2016;9:2189-2199.

7. Chamandi C, Barbanti M, Munoz-Garcia A, Latib A, Nombela-Franco L, GutierrezIbanez E, Veiga-Fernandez G, Cheema AN, Cruz-Gonzalez I, Serra V, Tamburino C, Mangieri A, Colombo A, Jimenez-Quevedo P, Elizaga J, Lee D-H, Garcia Del Blanco B, Puri R, Cote M, Philippon F, Rodes-Cabau J. Long-Term Outcomes in Patients With New-Onset Persistent Left Bundle Branch Block Following TAVR. JACC Cardiovasc Interv 2019;12:1175-1184.

8. Nazif TM, Chen S, George I, Dizon JM, Hahn RT, Crowley A, Alu MC, Babaliaros V, Thourani VH, Herrmann HC, Smalling RW, Brown DL, Mack MJ, Kapadia S, Makkar R, Webb JG, Leon MB, Kodali SK. New-onset left bundle branch block after transcatheter aortic valve replacement is associated with adverse long-term clinical outcomes in intermediate-risk patients: an analysis from the PARTNER II trial. Eur Heart $J$ 2019;40:2218-2227.

9. Jorgensen TH, De Backer O, Gerds TA, Bieliauskas G, Svendsen JH, Sondergaard L. Mortality and Heart Failure Hospitalization in Patients With Conduction Abnormalities After Transcatheter Aortic Valve Replacement. JACC Cardiovasc Interv 2019;12:52-61. 
10. Mohananey D, Jobanputra Y, Kumar A, Krishnaswamy A, Mick S, White JM, Kapadia SR. Clinical and Echocardiographic Outcomes Following Permanent Pacemaker Implantation After Transcatheter Aortic Valve Replacement: Meta-Analysis and MetaRegression. Circ Cardiovasc Interv 2017;10.

11. Regueiro A, Abdul-Jawad Altisent O, Del Trigo M, Campelo-Parada F, Puri R, Urena M, Philippon F, Rodes-Cabau J. Impact of New-Onset Left Bundle Branch Block and Periprocedural Permanent Pacemaker Implantation on Clinical Outcomes in Patients Undergoing Transcatheter Aortic Valve Replacement: A Systematic Review and MetaAnalysis. Circ Cardiovasc Interv 2016;9:e003635.

12. Faroux L, Chen S, Muntané-Carol G, Regueiro A, Philippon F, Sondergaard L, Jorgensen TH, Lopez-Aguilera J, Kodali S, Leon M, Nazif T, Rodes-Cabau J. Clinical Impact of Conduction Disturbances in Transcatheter Aortic Valve Replacement Recipients. A Systematic Review and Meta-Analysis. Eur Heart J 2019;

13. Van Belle E, Vincent F, Labreuche J, Auffret V, Debry N, Lefevre T, Eltchaninoff H, Manigold T, Gilard M, Verhoye J-P, Himbert D, Koning R, Collet J-P, Leprince P, Teiger E, Duhamel A, Cosenza A, Schurtz G, Porouchani S, Lattuca B, Robin E, Coisne A, Modine T, Richardson M, Joly P, Rioufol G, Ghostine S, Bar O, Amabile N, Champagnac D, et al. Balloon-Expandable versus Self-Expanding Transcatheter Aortic Valve Replacement: A Propensity-Matched Comparison from The France-TAVI Registry. Circulation 2019; doi: 10.1161/CIRCULATIONAHA.119.043785.

14. Deharo P, Bisson A, Herbert J, Lacour T, Saint Etienne C, Grammatico-Guillon L, Porto A, Collart F, Bourguignon T, Cuisset T, Fauchier L. Impact of Sapien 3 BalloonExpandable Versus Evolut R Self-Expandable Transcatheter Aortic Valve Implantation in 
Patients with Aortic Stenosis: Data from a Nationwide Analysis. Circulation 2019; doi: 10.1161/CIRCULATIONAHA.119.043971. 


\section{Take-home figure legend}

\section{Summary of the potential clinical impact of post-TAVI conduction disturbances and future directions to prevent their occurrence and improve their management.}

EP: Electrophysiologists; EPS: Electrophysiological studies; HAVB: high-degree atrioventricular block; LBBB: left bundle branch block; LVEF: left ventricular ejection fraction; LVOT: left ventricular outflow tract; PPI: Permanent pacemaker implantation; TAVI: Transcatheter aortic valve implantation.

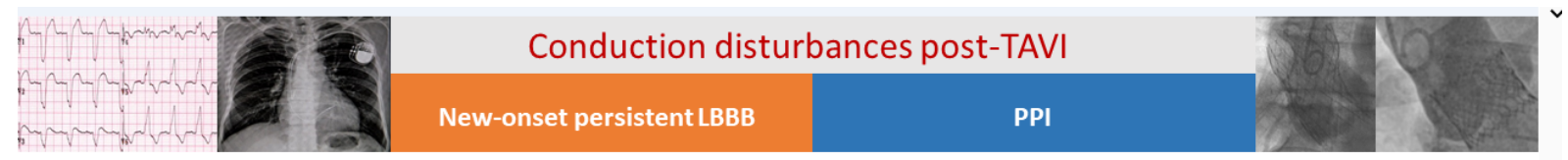

True causality or « innocent » bystanders of a poor prognosis among patients with more evolved heart disease?

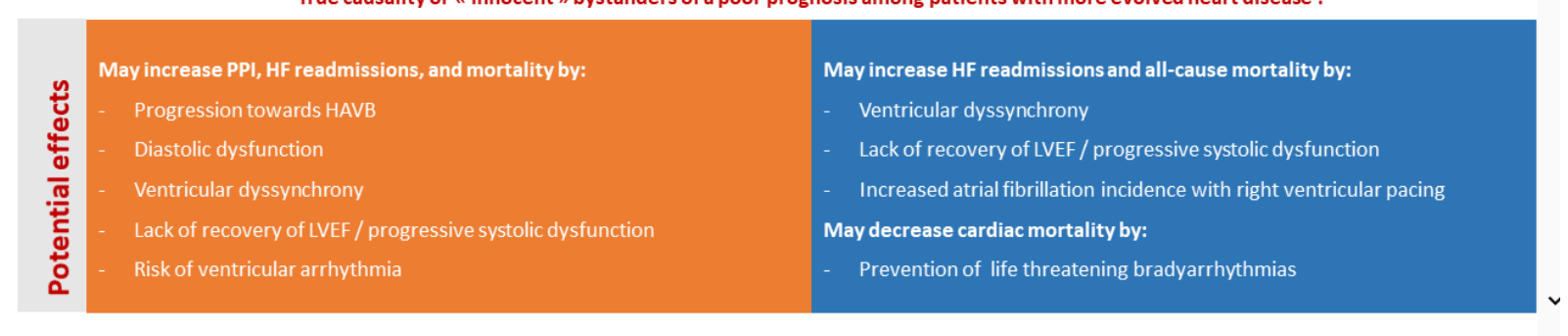

Paramount importance of preventing these complications: appropriate sizing of THVs, optimal deployment technique aiming at a more aortic position

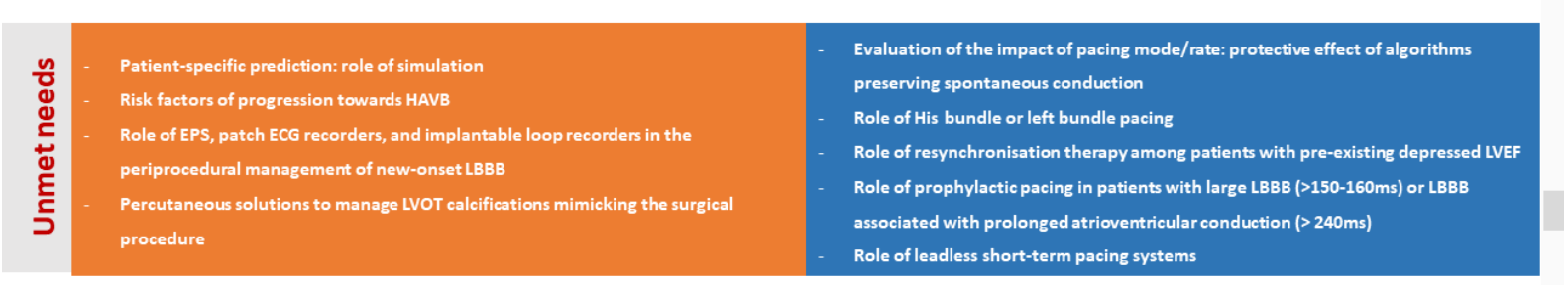

Crucial role of a close collaboration between interventional cardiologists and EP in routine practice and future research 
